\title{
Open Dump Simulation for Estimation of Pollution Levels in Wet Tropical Climates
}

\author{
R.T.K. Ariyawansha, B.F.A. Basnayake, K.P.M.N. Pathirana and A.S.H. Chandrasena
}

\author{
Center for Renewable Energy Sources \\ Postgraduate Institute of Agriculture \\ University of Peradeniya
}

\begin{abstract}
Leachate management is one of the major issues in rehabilitation of present dumpsites. A field scale 'lysimeter' study for open dump simulation of municipal solid waste with $940 \mathrm{~kg} / \mathrm{m}^{3}$ placement density was carried out to determine decomposition pattern of waste, namely the quality and quantity of leachate generations in wet tropical climates for 4 years. The study entailed the development of an analytical model to determine mass and water balances.
\end{abstract}

The percentage dry weight reduction of organic matter was $83 \%$ in the 4 year period. The prediction from the mass balance model gave an evapotranspiration coefficient of 0.826. The classical 'logistic growth' kinetics used in the analysis by considering the cumulative solid content (CSC) in leachate as the microbial substrate complex discharged and it was the key factor used to determine the pollution levels. CSC in leachate showed four distinct phases considered as three growth curves and a straight-line relationship with time. Three growth curves separated and simulated the solid content discharges in each of the phases. The times for the maximum solid discharge rate for each phase were 17, 150, and 349 days, respectively from waste placement. In applying to actual dumpsite conditions, all of the CSC values of the three phases (727 days) become a day's event. In an 'effective rainfall event', the minimum CSC discharge should be $24,859.5 \mathrm{~g}$. The maximum CSC is 49,684 g. The Biological Oxygen Demand $\left(B O D_{5}\right)$ values at the maximum substrate utilization rate for first and second phases were $18937 \mathrm{mg} / \mathrm{L}$ and $1775 \mathrm{mg} / \mathrm{L}$. Therefore, maximum aggregated $\mathrm{BOD}_{5}$ value should be $9781.5 \mathrm{mg} / \mathrm{L}$. Further studies are required towards modeling deep dumpsites.

\section{INTRODUCTION}

Open dumping is unfortunately still a prevalent method of final disposal of Municipal Solid Waste (MSW) which is practiced by about three fourths of the countries and territories in the world (Joseph et al., 2005). The waste dumped in an uncontrolled manner (Nagendran et al., 2006) can be harmful to the urban environment. This problem has become one of the primary urban environmental issues along with the accelerated generation of waste caused by an ever increasing population, urbanization and industrialization (Trankler et al., 2005). Open dumping of MSW with higher organic content further aggravates problems due to formation of large amount of highly polluted leachate and landfill gases. That leads to create a long term threat to public health, water resources, land resources, air, and biodiversity in the country (Nagendran et al., 2006; Gunawardana et al., 2009).

The dumpsites cause environmental degradation since they are susceptible to open burning, groundwater pollution and exposed to scavengers and disease vectors (Karthikeyan et al., 
2007). Most of these dumpsites are very close to highly populated urban areas and does not have enough capacity to receive waste for long time (Gunawardana et al., 2009). Those unsafe dumpsites are essential to be rehabilitated in order to preserve the environment and to find space for fresh MSW (Zhou et al., 2007). Reclamation and rehabilitation of dumpsites have been used as tools for sustainable land filling throughout the world for the last fifty years (Joseph et al., 2005). During the rehabilitation of a dumpsite, leachate management is one of the major issues. The key limitation for successful treatment of landfill leachate is the difficulty in identifying and quantifying a typical composition and characteristics. In literature, very limited information exists on the interaction between the tropical climate and leachate composition and generation (Trankler et al., 2005).

A field scale lysimeter study for open dump simulation of MSW was conducted to observe decomposition pattern of waste, in terms of quality and quantity of leachate generation under wet tropical climates. This paper is aimed at estimating the maximum strength of leachate and the duration to attain such values for designing of leachate management systems. Thus, it entailed evaluation of the climatic parameters that affect the leachate generation with the aid of the lysimeter study. The classical 'logistic growth' kinetics was used in the analysis.

\section{MATERIALS AND METHODS}

A field scale lysimeter experiment simulating a dumpsite with fresh MSW was conducted at the Department of Agricultural Engineering, University of Peradeniya, Sri Lanka. This was a long term research conducted from $1^{\text {st }}$ April 2003 to $13^{\text {th }}$ June 2008.

\section{Experimental setup}

The experiment setup of the constructed lysimeter is given in the Fig. 1. A lysimeter was built using concrete rings with the diameter of $1.3 \mathrm{~m}$. The height of the lysimeter was $3.32 \mathrm{~m}$. A depth of $2.32 \mathrm{~m}$ of lysimeter was below the ground level and the rest of the lysimeter was above the ground level. A gravel pack was placed at the bottom of the lysimeter to facilitate the filtration of leachate and their movement. The bottom of the lysimeter was constructed with a slope towards the front side. At the end of the slope, there was a leachate collecting pipe and $3498.1 \mathrm{~kg}$ of fresh MSW were placed with $940 \mathrm{~kg} / \mathrm{m}^{3}$ placement density.

Leachate samples were taken from the lysimeter once a week to analyze for various parameters that represent the processes. The monitored parameters were leachate quality and quantity. The ambient parameters like temperature, rainfall, and pan-evaporation were measured at the site of experiment. Leachate generation and waste settlement were measured daily. Standard methods were followed to analyze the samples for chemical parameters. Final weight of the waste mass of the lysimeter and moisture content were analyzed in order to obtain the mass balance. 


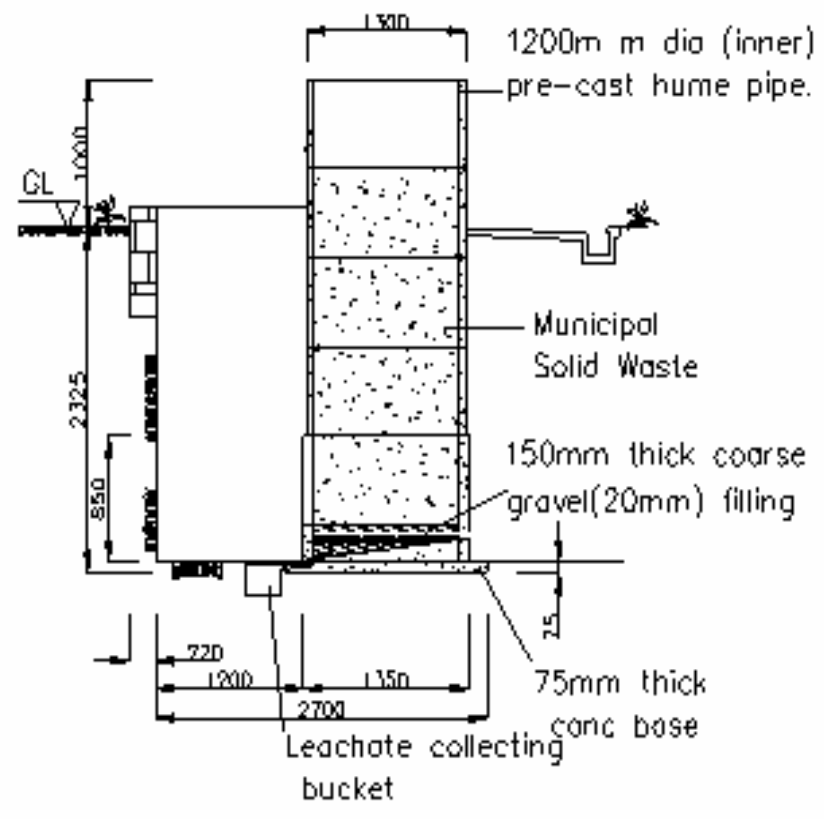

Fig. 1. Experiment setup of the field scale lysimeter

\section{Estimation of the water balance}

In an in situ lysimeter, it is difficult to obtain some of the dynamic behaviors such as changes in weight, moisture and evapotranspiration (ET) to determine the mass and water balances during the monitoring period. However, it is possible to predict those parameters once initial and final wet and dry weights of the raw wastes and decomposed wastes are known, assuming that a fraction of pan evaporation (ETp) is evaporated, such that:

$$
\mathrm{ET}=\mathrm{Co} \mathrm{x} \mathrm{ETp}
$$

Where, ET = Evapotranspiration in $\mathrm{mm}$

$\mathrm{ETp}=$ Pan evaporation in $\mathrm{mm}$

$\mathrm{Co}=$ Coefficient of evapotranspiration of open dump

Although this assumption may not be exact, it could be based on the finding that the pan evaporation values were found to be proportional to short grass ET as stated by Hagan et al. (1967). The leachate generation rate in the active condition as reported by Qian et al. (2002) is denoted by the following equation.

$$
\mathrm{L}_{\mathrm{A}}=\mathrm{P}+\mathrm{S}-\mathrm{E}-\mathrm{WA}
$$

Where, $\mathrm{L}_{\mathrm{A}}=$ Leachate rate in the active condition

$\mathrm{P}=$ Precipitation

$\mathrm{S}$ = Pore squeeze liquid from waste

$\mathrm{E}=$ Moisture lost through evaporation

$\mathrm{WA}=$ Waste moisture absorption 
In order to estimate the waste moisture absorption, equation 2 can be rearranged as equation 3 ,

$$
\mathrm{WA}=\mathrm{P}+\mathrm{S}-\mathrm{E}-\mathrm{L}_{\mathrm{A}}
$$

Squeeze liquid from waste and leachate generation due to precipitation contribute to leachate drain out from the system. Hence based on the equation 3, the water balance estimations in the lysimeter was achievable using equation 4 from initial to final conditions of $t=0$ to $t=n$ as stated below.

$$
\sum_{t=0}^{t=n} W m=W m_{t=0}+\sum_{t=0}^{t=n} P-C_{0} \sum_{t=0}^{t=n} E T_{p}-\sum_{t=0}^{t=n} L_{A}
$$

Where, $\quad \mathrm{Wm}=$ Moisture content of wastes in $\mathrm{mm}$

\section{Kinetic analysis}

The basis for developing the kinetic analysis was on the assumption that a defined decomposition of the wastes is taking place and the leachate was an outcome. The parameter of total solids (TS) was the key factor used to determine the pollution levels in terms of Biochemical Oxygen Demand (BOD), since monitoring of COD was expensive. The difference between values of TS in relation BOD gives ion concentrations. Therefore, the solid content of the leachate at time $t_{n}$, is estimated by equation 5 .

$$
\mathrm{SD}_{\mathrm{tn}}=\mathrm{L}_{\mathrm{tn}} \times \mathrm{TS}_{\mathrm{tn}}
$$

Where, $\mathrm{SD}_{\mathrm{tn}}=$ Solid content in leachate drained in $\mathrm{g}$

$\mathrm{L}_{\mathrm{tn}}=$ Leachate quantity in litres at time $\mathrm{t}$

$\mathrm{TS}_{\mathrm{tn}}=$ Total solid concentration in $\mathrm{g} /$ litre at time $\mathrm{t}$

Therefore, the cumulative solid content at time $\mathrm{t}_{\mathrm{n}}$ is calculated as $\sum_{t=0}^{t=n} S D$. Cumulative solid content (CSC) is considered as the microbial substrate complex discharged. It has been assumed that all of the parameters that depend on microbial growth in the lysimeter follows the following logistic growth curve.

$$
X_{t}=\frac{\alpha X_{0} e^{\alpha t}}{\beta X_{o} e^{\alpha t}+\alpha-\beta X_{0}}
$$

Where, $X_{t}=$ Biological transformation mass at time $\mathrm{t}$

$X_{o}=$ Initial value of (reactive) growth

$\alpha=$ Transformation or growth coefficient

$\beta=$ Retardation coefficient

The first derivative

$$
\frac{d X_{t}}{d t}=\alpha X_{t}-\beta X_{t}^{2}
$$


Microsoft Excel programme has been developed to obtain the above coefficients and $\mathrm{X}_{\mathrm{o}}, \frac{\alpha}{\beta}$. Regression analysis was conducted to obtain $\mathrm{R}^{2}$. The program optimizes the value of $\frac{\alpha}{\beta}$ to give the optimum $\mathrm{R}^{2}$ value. When the first derivative $\frac{d X_{t}}{d t}$ is equated to the transformation rate, $\operatorname{Tr}$ and differentiated with respect to $X_{t}$, i.e. obtain

$$
\frac{d T r}{d X_{t}}=\alpha-2 \beta X_{t}
$$

and at the maximum value of the transformation rate, the slope is equal to zero. Therefore, the maximum growth utilizing the substrate is;

$$
X_{t}=\frac{\alpha}{2 \beta}
$$

Substituting $\frac{\alpha}{2 \beta}$ in equation (6), the time for maximum (solid discharges) growths could be found (Paramsothy et al., 2004; Sasikala et al., 2005; Basnayake et al., 2006).

$$
\begin{gathered}
\frac{\alpha}{2 \beta}=\frac{\alpha X_{0} e^{\alpha t}}{\beta X_{0} e^{\alpha t}+\alpha-\beta X_{0}} \\
\alpha \beta X_{0} e^{\alpha t}=\alpha^{2}-\alpha \beta X_{0} \\
e^{\alpha t}=\frac{\alpha^{2}-\alpha \beta X_{0}}{\alpha \beta X_{0}} \\
t_{\max }=\frac{1}{\alpha} \ln \left(\frac{\alpha}{\beta X_{0}}-1\right)
\end{gathered}
$$

\section{RESULTS AND DISCUSSION}

\section{Mass balance analysis}

Table 1 gives the summary of mass balance of the lysimeter. The percentage dry weight reduction of organic matter was $83 \%$. It must have formed organic acids to reduce the metal (cans) content significantly. Under anaerobic conditions, although at high placement density, the decomposition was high in open dumping. 


\section{Water balance analysis}

The water balance study provides a means to determine net evapotranspirations (ET) in an open dumpsite. The analysis adopted necessitated to know the initial and final moisture contents of the wastes inside the lysimeter. The main assumption was that the ETp is proportional to ET. Therefore, it is equal to ET, when ETp is multiplied by a coefficient. In fact, cumulative ETp is linear over a defined period or a season (Fig. 2) over number of seasons. In comparison, the cumulative value of ET may not be linear, since both saturated and unsaturated conditions do exist in the simulation study and landfills. However, under wet tropical conditions, a saturation zone was identified in the middle of the $3 \mathrm{~m}$ height lysimeter (Basnayake et al., 2008). Thus, there might have been freely available moisture. Like in the case of bare soil, ET is less than ETp and thus the coefficient is less than one.

Table 1. Composition and mass balance analysis of lysimeter

\begin{tabular}{lrrrrrr}
\hline Composition & $\begin{array}{c}\text { Initial } \\
\text { Fresh } \\
\text { Weight } \\
\text { (Kg) }\end{array}$ & $\begin{array}{c}\text { Initial \% } \\
\text { (wet) }\end{array}$ & $\begin{array}{c}\text { Initial Dry } \\
\text { Weight (Kg) Weight (Kg) }\end{array}$ & $\begin{array}{c}\text { Final \% } \\
\text { (wet) }\end{array}$ & $\begin{array}{c}\text { Final Dry } \\
\text { Weight (Kg) }\end{array}$ \\
\hline Organic & 3113.31 & 89.00 & 1263.75 & 988.40 & 72.98 & 213.15 \\
Plastic /Polythene & 221.78 & 6.34 & 221.78 & 221.78 & 16.38 & 221.78 \\
Glass & 18.19 & 0.52 & 18.19 & 18.19 & 1.34 & 18.19 \\
Metal (cans) & 19.59 & 0.56 & 19.59 & 9.79 & 0.72 & 9.79 \\
Clay / inert & 116.14 & 3.32 & 47.14 & 116.14 & 8.58 & 25.04 \\
Others & 9.10 & 0.26 & 3.69 & 0.00 & 0.00 & 0.00 \\
Total & 3498.10 & 100.00 & 1574.15 & 1354.30 & 100.00 & 487.95 \\
\hline
\end{tabular}

\section{Estimation of ET coefficient}

According to mass balance analysis, initial $\left(\mathrm{Wm}_{\mathrm{t}=0}\right)$ and final $\left(\mathrm{Wm}_{\mathrm{t}=\text { fnal }}\right)$ moisture contents expressed in heads are $1700.5 \mathrm{~mm}, 765.7 \mathrm{~mm}$, respectively. Then water balance equation can be used for the final condition.

The coefficient was determined by equation 4 . It was equal to 0.826 which is comparable to bare soil. The predicted cumulative value of ET is plotted in Fig. 2. However, there could be fluctuations, since landfill gases too compete with the moisture in the processes of emissions. The gas emissions may increase or decrease evaporations, particularly with increased microbial activity, it may increase ET. Such rapid moisture removals take place in the first few weeks after disposing the wastes. Under aerobic conditions, the temperature rise and vapour removal is dominant until anaerobic conditions sets in (Reinhart and Townsend, 1998).

The quantity of leachate generation is affected by many factors such as, precipitation, moisture content and density of waste, evaporation and gas production (Al-Yaqout and Hamoda, 2003; Gunawardena et al., 2009). However, the precipitation represents the largest single contribution for the generation of leachate (Koerner and Daniel, 1997; Reinhart and Townsend, 1998; Gálvez et al., 2009) in open dumps. The cumulative values of rainfall and leachate productions was plotted to demonstrate the close relationship between the two values (Fig. 2). There were noticeable contents of leachate formed above the quantum of rainfall in the entire 423 days after dumping. 


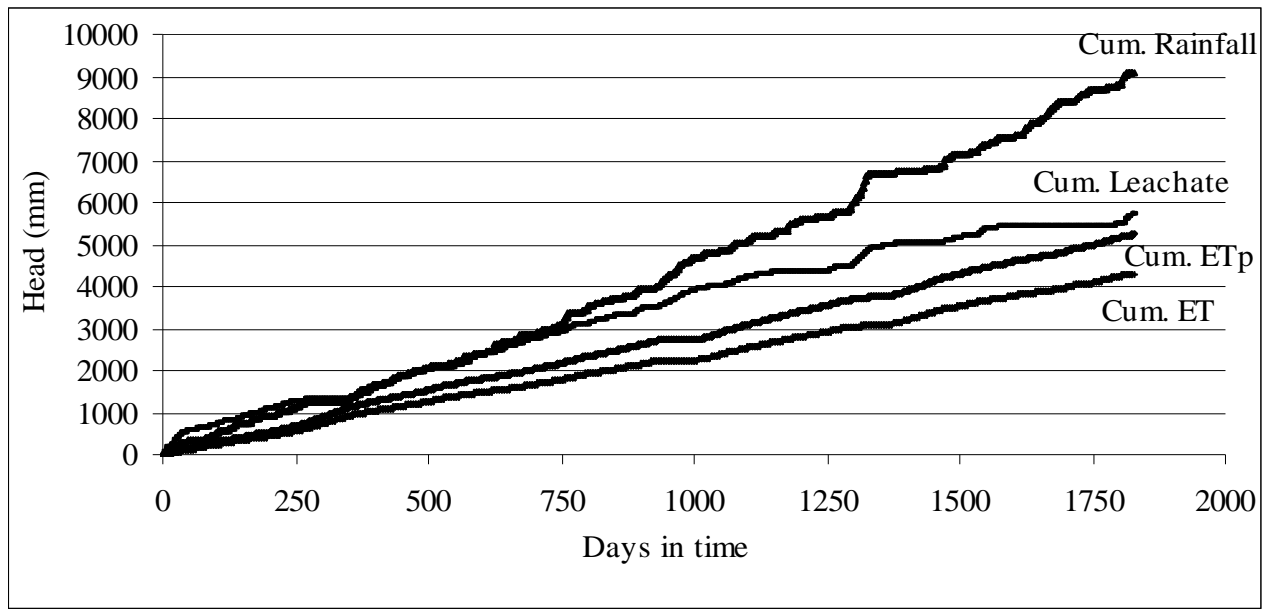

Fig. 2. Temporal variations of components of the water balance

\section{Sorption properties}

Moisture content depends on the absorption and desorption properties, the microbial activities change both absorption and de-sorption properties with time, and it is much more dynamic under tropical climatic conditions. As shown in Fig. 3 at the initial stage, the rate of decomposition of waste and the quantum of leachate generation were much higher due to higher microbial activities. Along with this, the rate of settlement was also high. Thus, the desorption took place as shown in Fig. 3 indicating negative values. It is evident that the waste gradually reached stabilization, since physical characteristics such as porosity and permeability increased, along with absorption. This increase in sorption properties with time prevented leachate emissions. However, there was mechanical settlement as reported by many (Qian et al., 2002; Gunawardana et al., 2009), decreasing some of the physical properties, but it gradually increased with increased decomposition to eventually become very absorbent as indicated in the latter part of the experiment.

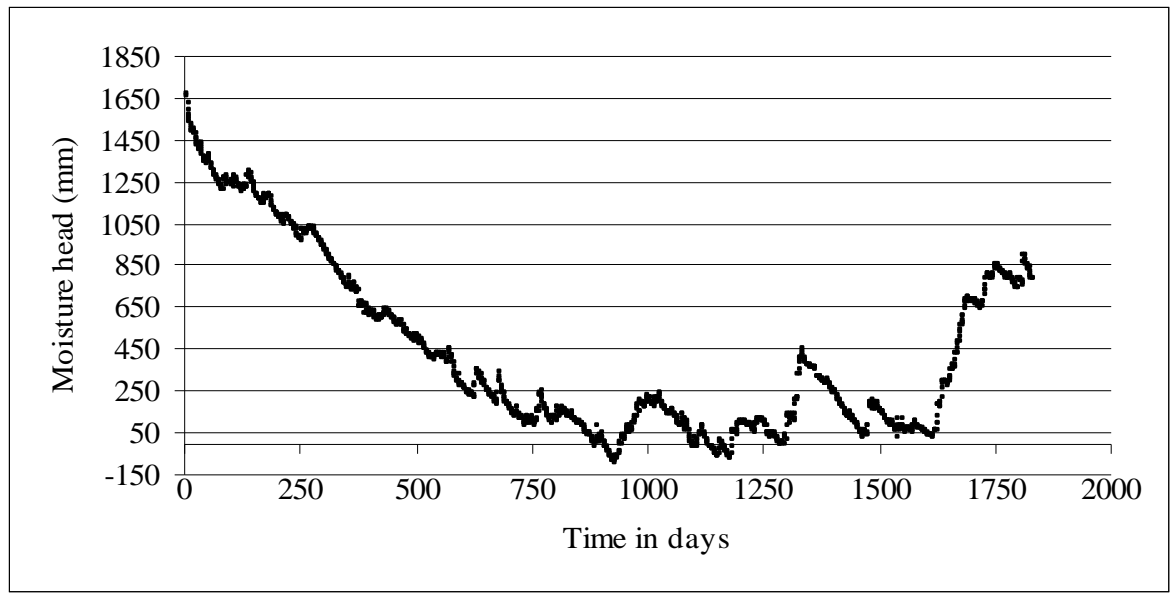

Fig. 3. Temporal variations of sorption properties of decomposing waste 


\section{Logistic growth equations}

The chemical composition of leachate depends on many factors such as the initial composition of solid wastes, the particle size, the degree of compaction, the hydrology of the site, the climate, and finally the age of tip (Al-Yaqout and Hamoda, 2003; Trankler et al., 2001). Cumulative solids content in leachate showed four distinct phases which can be considered as three growth curves and a straight line relationships with time as shown in Fig. 4. Three growth curves separated and simulated the solid content discharges in each of the phases using equation 6.

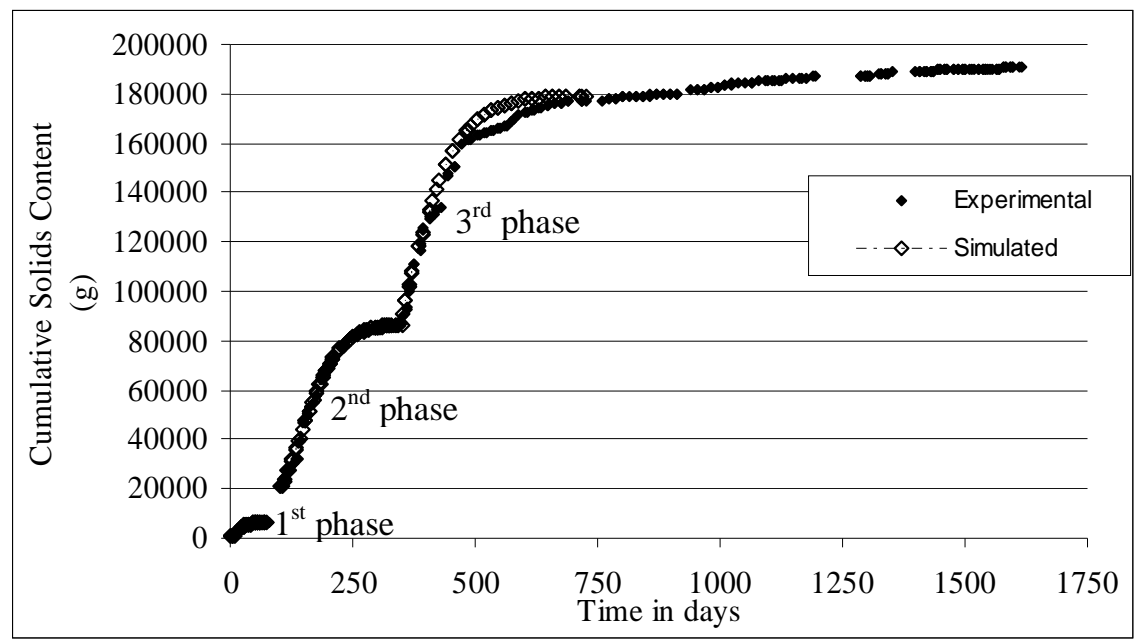

\section{Fig. 4. Cumulative solid content in leachate variations with time}

Logistic growth parameters for each phase are given in Table 2. Experimental and simulated solids variations for first, second and third phases are shown in Fig. 5. The maximum substrate utilizing rate for the third phase showed a negative value indicating that the maximum substrate utilization rate was not within the third phase, but the event was in the second phase. The delayed response was perhaps due to prolonged dry spells with events of rainfall being absorbed as mentioned above. The actual time of maximum substrate utilizing rate for the second and third phases were 150 days and 349 days respectively from waste placement.

Table 2. Logistic growth parameters for each phase

\begin{tabular}{lrrr}
\hline Parameter & First phase & Second phase & Third phase \\
\hline $\mathrm{X}_{\mathrm{o}}$ & 700 & 21028.46 & 90219.31 \\
$\alpha$ & & & \\
$\beta$ & 6086.7 & 87875.6 & 178985.5 \\
$\mathrm{R}^{2}$ & & & \\
$\mathrm{t}_{\max }$ & 0.9793 & 0.9953 & 0.9863 \\
\hline
\end{tabular}




\section{Prediction of pollutions from dumpsites}

In order to develop a rational mathematical reasoning to utilize lysimeter simulation in actual dumpsites, it is necessary to consider each day's solid discharges. Thus, it is possible to consider the cumulative solid content (CSC) as the sum of events that had taken place from the time of disposal. In the case of the simulation data applied to actual dumpsite conditions, all of the CSC values of 727 days become a day's event, meaning CSC from fresh wastes to old wastes disposed since 727 days. In this hypothetical case, all of the wastes have been disposed thinly at $3.32 \mathrm{~m}$ of the height of the lysimeter. After 727 days of disposal, the minimum CSC for a rainfall event exceeding maximum sorption capacity, should be at a discharge event when maximum transformation had taken place inside the landfill body, naming it as 'an effective rainfall event'. In other words, it is the CSC at the time when $X_{t}=$ $\alpha / 2 \beta$ for each of the phases.

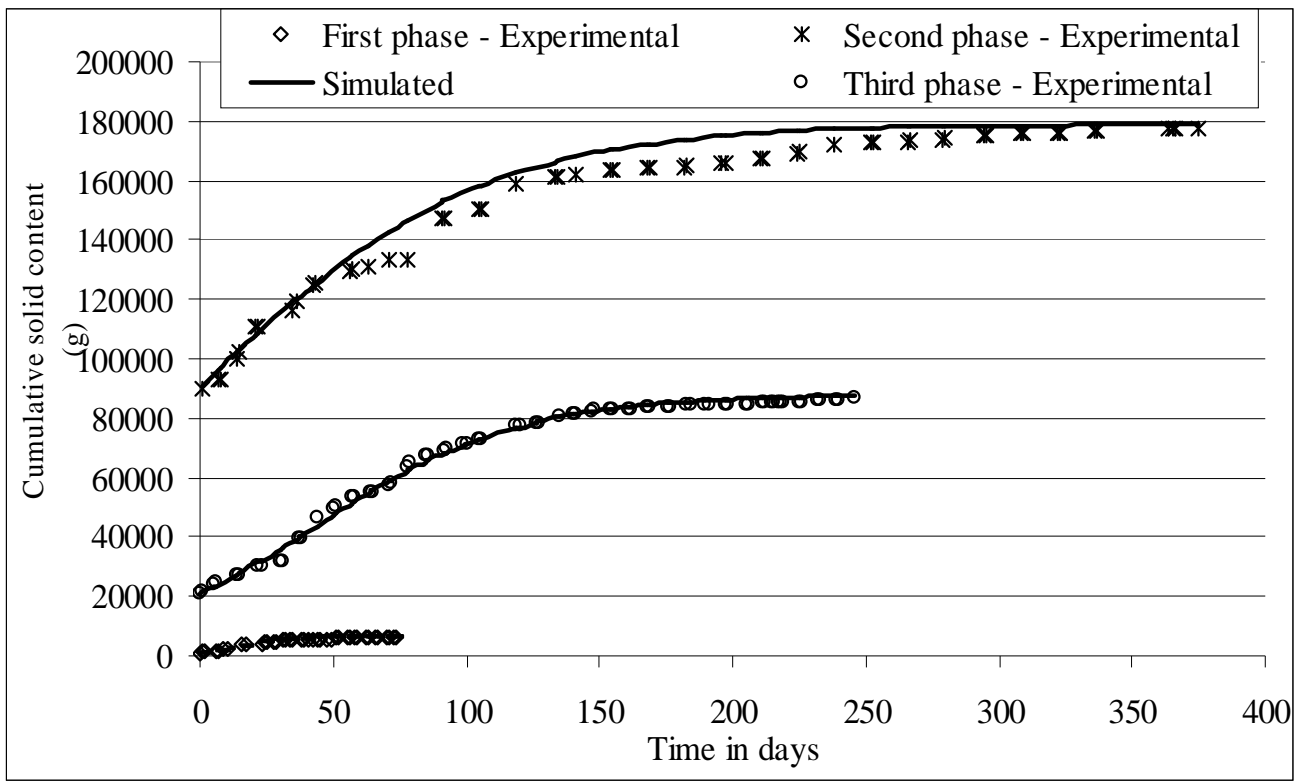

\section{Fig. 5. Experimental and predicted cumulative solids variations in three phases}

In a given effective rainfall event, there could either be two or three phases. In the case of minimum CSC, consideration should only be for two phases. The basis for determining the numerical value is on the rational of proportional quantities of leachate generations for each of the phases. Therefore, minimum and maximum CSC content in each phase can be calculated using equation 11 and equation 12 respectively and values are given in Table 3 . The minimum CSC is $24859.5 \mathrm{~g}$. It stands to reason in determining the maximum value, since it is possible to obtain the maximum CSC values for each of the phases based on the fraction of leachate emissions in relation to total emissions. The maximum CSC is $49,684 \mathrm{~g}$.

The Minimum CSC in phase $=\alpha / 2 \beta$ of first phase $\mathrm{x}$ Leachate in first or second phase ----(11)

Leachate of first + second phase 
Ariyawansha et al.

The Maximum CSC in phase $=\alpha / \beta$ of first phase $\mathrm{x}$ Leachate in first or second phase --- (12)

Leachate of first + second phase

Table 3. Calculated CSC content in each phase

\begin{tabular}{lccrrr}
\hline Phase & $\frac{\alpha}{2 \beta}$ & $\frac{\alpha}{\beta}$ & $\begin{array}{c}\text { Leachate } \\
\text { Quantity (l) }\end{array}$ & $\begin{array}{c}\text { Minimum } \\
\text { CSC (g) }\end{array}$ & $\begin{array}{c}\text { Maximum } \\
\text { CSC (g) }\end{array}$ \\
\hline $1^{\text {st }}$ & 3043.36 & 6086.71 & 704.5 & 1419.8 & 2839.6 \\
$2^{\text {nd }}$ & 43937.8 & 87875.6 & 805.6 & 23439.7 & 46844.5 \\
\hline
\end{tabular}

A similar analytical approach is possible with the $\mathrm{BOD}_{5}$. Unfortunately, the cumulative values of $\mathrm{BOD}_{5}$ are not consistent, since they are not the ultimate values. Thus, an indirect method is to consider maximum and minimum CSC values and relate them to $\mathrm{BOD}_{5}$. The maximum $\mathrm{BOD}_{5}$ value is likely to be at the minimum of CSC value for a given phase of CSC. Therefore, knowing the time to reach the minimum value of $\mathrm{CSC}$, the corresponding $\mathrm{BOD}_{5}$ value furnished from Fig. 6, but the most likely value is calculated based on proportionate leachate emissions for each phase. The $\mathrm{BOD}_{5}$ values at the maximum substrate utilization rate for first and second phase are $18937 \mathrm{mg} / \mathrm{l}$ and $1775 \mathrm{mg} / \mathrm{l}$ according to Fig. 6. The weighted $\mathrm{BOD}_{5}$ value for the first phase calculated as follows.

Maximum $\mathrm{BOD}_{5}$ in first phase $=18937 \mathrm{mg} / \mathrm{l}$ x Leachate in first phase $\quad=8834.6 \mathrm{mg} / \mathrm{l}$ Leachate of first + second phase

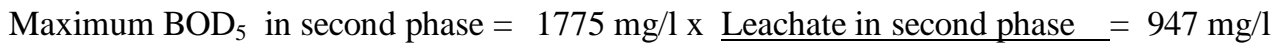
Leachate of first + second phase

Therefore, the weighted maximum $\mathrm{BOD}_{5}$ value for whole first and second phase should be $9781.5 \mathrm{mg} / \mathrm{l}$.

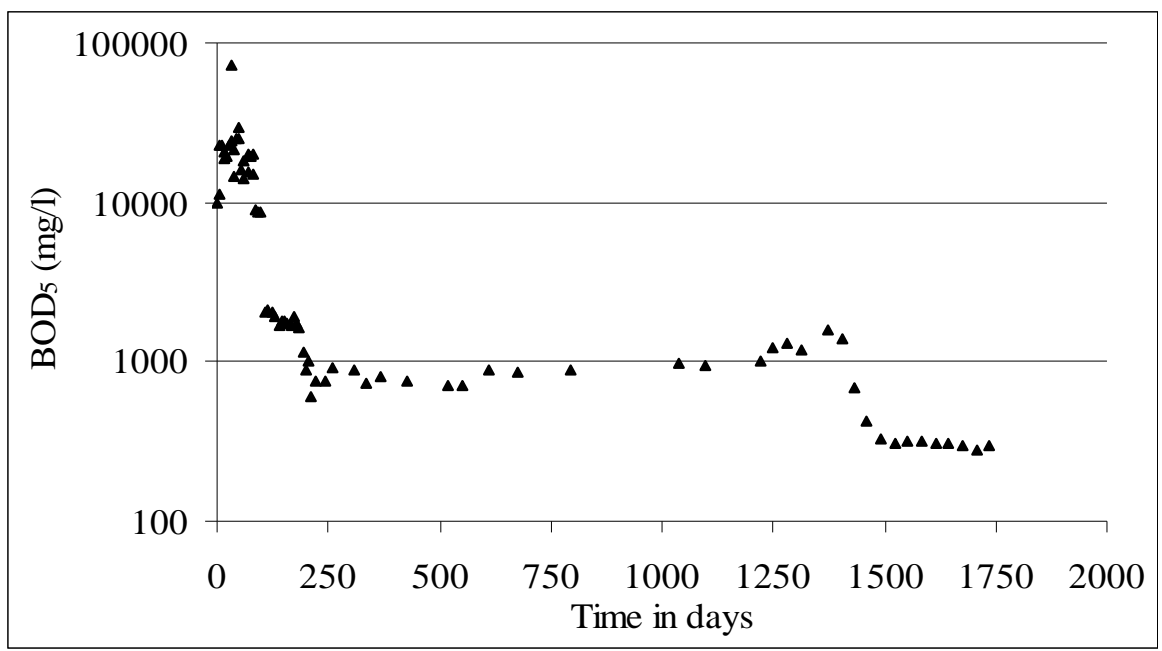

Fig. 6. Temporal variations of biochemical oxygen demand in leachate Shallow vs deep dumpsites 
The above evaluations are very valid for dumpsites having the same height of the lysimeter. Depending on the extent of the dumpsite, it may take more than or less than 727 days to fill one lift. Therefore, in defining and characterizing deep dumpsites, there are two predictable types, namely; one that reaches stabilization before completion of lift and the other incomplete stabilization. The stabilized deep dumps are very similar, then to shallow dumps, since the leachate discharges will be similar with slight additional strength in the leachate emitted from the final phase of curvilinear decomposition taking place of each layer with increase in height of dumpsite. However, as the height increases inorganic compounds and nitrogen concentrations makes the deeper layers toxic and the reactions ceases (Basnayke $e t$ al., 2008). In the case of number of lifts before stabilization can take place or even six meter deep lifts will have strong leachate strengths, since ET per unit area is the same and it can be predicted from the simulation study. However, as the dumps become deeper, the reactions cease and decomposition stops. In order to define and characterize the leachate emissions of such dumpsites, it may require at least one to two months of evaluating the leachate qualities to quantify accurately the pollution strengths of such dumps.

\section{CONCLUSIONS}

The predications of pollution levels and study on the effect of climatic parameters on leachate generation are very important for designing leachate treatment systems for rehabilitating dumpsites. With this intention, the performance of a field scale lysimeter for dumpsite simulation of municipal solid waste was evaluated. Under such conditions, decomposition of organic content was high, thus leaching metallic substances. The analysis on mass and water balances gave an accurate prediction on evapotranspiration coefficient for dumpsites under wet tropical climates.

The cumulative values of the solid content, immaterial of the quantity of leachate generated followed the classical 'logistic growth' kinetics thus, it was possible to predict the pollution levels. The basis for the rational was on the assumption that a defined decomposition of the wastes was taking place inside the landfill body. Thus, the leachate quality was an outcome, and the parameter of total solids (TS) was the key factor used to determine the pollution levels in terms of Biochemical Oxygen Demand (BOD). The developed methodology can predict both minimum and maximum values of the two parameters. It is applicable for shallow dumpsites corresponding to the height of simulation, but prediction of pollution levels of deep dumpsites is possible and it is the future aspiration of the continued study.

\section{ACKNOWLEDGEMENTS}

The Authors are most grateful to the Swedish International Development Agency (SIDA) and Asian Institute of Technology (AIT) for technical and financial support given for the project; Sustainable Solid Waste Landfill Management in Asia under the Regional Research Programme on Environmental Technologies (ARRPET). 


\section{REFERENCES}

Al-Yaqout, A.F. and Hamoda, M.F. (2003). Evaluation of landfill leachate in arid climate-a case study. J. Environ. Int. 29:593- 600.

Basnayake B.F.A., Visvanathan C., Wimalaweera. R.M. and Mannapperuma, N.R.C. (2006). Microbial reaction kinetics for correlating first phase anaerobic reactions in laboratory and pilot scale digesters. Asian J. Microbiol., Biotech. and En. Sci. 8(3): 405-411.

Basnayake, B.F.A., Karunarathne, S.A., Gunarathna, H.A.Y.R. and Murugathasan, S. (2008). Evaluation of reactivity and inhibitions in municipal solid waste dumpsites and landfills in the humid tropical regions in Sri Lanka. In: APPLAS, Sapporo, Hokkaido, Japan, 22-24 October, 2008.

Gálvez, A., Giusti, L., Zamorano, M. and Ramos-Ridao, A.F. (2009). Stability and efficiency of biofilms for landfill leachate treatment. J. Bioresour. Technol.

Gunawardana, E.G.W., Shimada, S., Basnayake, B.F.A. and Iwata, T. (2009). Influence of Biological Pre-treatment of Municipal Solid Waste on Landfil Behaviour in Sri Lanka. J. Waste Magt. Res.

Hagan, R.M., Haise, H.R. and Edminster, T.W. (1967). Irrigation of Agricultural Lands, American Society of Agronomy, Publisher Madison, Wisconsin, USA.

Joseph, K., Esakku, S., Nagendran, R. and Visvanathan, C. (2005). A decision making tool for dumpsite rehabilitation in developing countries. Tenth international waste management and landfill symposium S. Margherita di Pula, Cagliari, Italy; 3 - 7 October 2005.

Karthikeyan, O. P., Swati, M., Nagendran, R. and Joseph, K. (2007). Performance of bioreactor landfill with waste mined from a dumpsite. Environ Monit Assess: DOI 10.1007/s10661-007-9709-z.

Koerner, R.M. and Daniel, D.E. (1997). Final cover for solid waste landfills and abandoned Dump, ASCE Press. Reston, V.A and Thomas Telford, London, UK.

Nagendran, R., Selvam, A., Joseph, K. and Chiemchaisri, C. (2006). Phytoremediation and rehabilitation of municipal solid waste landfills and dumpsites: A brief review. J. Waste Mgt 26: $1357-1369$.

Paramsothy, A., Wimalaweera, R.M., Basnayake, B.F.A. and Wijesinghe, D.T.N. (2004). Optimizing Hydrolyss/Acidogenesis Anaerobic Reactor with the Application of Microbial Reaction Kinetics. Tropic. Agric. Res. 16.

Qian, X., R. M. Koerner, and Gray, D. H. (2002).Geotechnical aspects of landfill design and construction. Prentice-Hall, New Jersey, NY

Reinhart, D.R. and Townsend, T.G. (1998). Landfill bioreactor design and operation, CRC Press LLC, 2000, Boca Raton., FL, 3. 
Sasikala, S., Mowjood, M.I.M. and Basnayake, B.F.A. (2005). Formulation of harvesting regimes from Bulrush (Scirpus grossus L.f.) growth responses to MSW leachate in constructed wetlands with coir-based Media. J. Tropic. Agric. Res. 17:125.

Trankler, J., Manandhari, D.R., Xiaoning, Q., Silvapornpun, V. and Scholl, W. (2001). Effects of monsoon conditions on the management of landfill leachate in tropical countries.2:59-68. In: $8^{\text {th }}$ international waste management and landfill symposium, Pula, Cagliari, Italy.

Trankler, J., Visvanathan, C., Kuruparan, P. and Tubtimthai, O. (2005). Influence of tropical seasonal variations on landfill leachate characteristics-Results from lysimeter studies. J. Waste Mgt 25:1013-1020.

Zhou, G., Chen, D. and Cui, W. (2007). Comparison between fresh and aged municipal solid wastes and their recycling methods in china. In: Eleventh International Waste Management and Landfill Symposium, S. Margherita di Pula, Cagliari, Italy, 1 - 5 October 2007. 